remission of symptoms and signs in about $60 \%$ of patients both acutely ${ }^{18}$ and on follow up. ${ }^{13}$ More recently, the first indications that this form of treatment may slow or halt progression of disease have been seen. ${ }^{1}$ It is therefore of considerable interest to find that the spheroplasts of $H$ influenzae studied here possessed a cell wall and that this was not completely defective ( $\mathrm{L}$ forms) as had been assumed. ${ }^{511}{ }^{13}$ Appropriate dose antibiotic treatment may well inhibit formation or even destroy the reservoir of such "persister" spheroplasts, and this may be one reason for the success of this approach. In the context it is notable that rapid (within a few days) return of pus in sputum after stopping conventional antibiotic treatment is associated with much more frequent isolation $(70 \%)$ of $H$ influenzae, whereas late recurrence (weeks or months) is associated equally with $H$ influenzae $(55 \%$ ) and Streptococcus pneumoniae $(55 \%){ }^{2}$

It is possible that spheroplastic $H$ influenzae contain tissue damaging substances and, if this is the case, it may be important to inhibit their formation by using a dose of antibiotic that will achieve a bactericidal concentration in the secretions-not merely a bacteriostatic concentration, which may encourage emergence of such forms.

We are grateful to colleagues at Brompton Hospital for allowing us to study the sputum of their patients. EH is supported by Bencard. The work was supported by the Wellcome Trust.

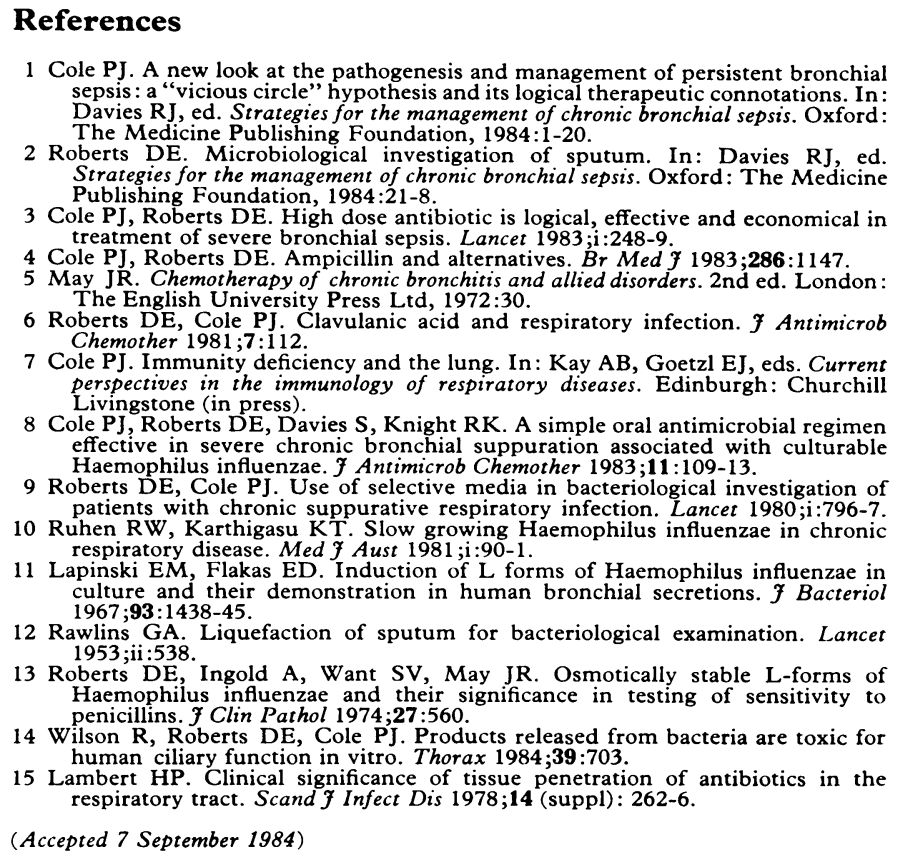

1 Cole PJ. A new look at the pathogenesis and management of persistent bronchial sepsis: a "vicious circle" hypothesis and its logical therapeutic connotations. In Davies RJ, ed. Strategies for the management of chronic bronchial sepsis. Oxford:

2 Roberts DE. Microbiological investigation of sputum. In: Davies RJ, ed. Strategies for the management of chronic bronchial sepsis. Oxford: The Medicine Publishing Foundation $1984: 21-8$.

3 Cole PJ, Roberts DE. High dose antibiotic is logical, effective and economical in treatment of severe bronchial sepsis. Lancet $1983 ; \mathrm{i}: 248-9$

5 Cole PJ, Roberts DE. Ampicillin and alternatives. Br Med f 1983;286:1147. The English University Press Ltd, 1972:30.

Roberts DE, Cole PJ. Clavulanic acid and respiratory infection. $f$ Antimicrob
Chemother 1981;7:112. Cole PJ. Immunity deficiency and the lung. In: Kay AB, Goetzl EJ, eds. Current perspectives in the immunology of respiratory diseases. Edinburgh: Churchil

Livingstone (in press).
Cole PJ, Roberts DE, Davies S, Knight RK. A simple oral antimicrobial regimen effective in severe chronic bronchial suppuration associated with culturable Haemophilus influenzae. F Antimicrob Chemother 1983;11:109-13.

Roberts DE, Cole PJ. Use of selective media in bacteriological investigation of patients with chronic suppurative respiratory infection. Lancet $1980 ; 1: 796-7$ respiratory disease. Med $f$ Aust $1981 ; \mathrm{i}: 90$ - 1 .

11 Lapinski EM, Flakas ED. Induction of $\mathrm{L}$ forms of Haemophilus influenzae in culture and their demonstration in human bronchial secretions. $\mathcal{F}$ Bacteriol $1967 ; 93: 1438-45$.

12 Rawlins GA. Liquefaction of sputum for bacteriological examination. Lancet 1953;ii:538.

13 Roberts DE, Ingold A, Want SV, May JR. Osmotically stable L-forms of Haemophilus influenzae and their significance in testing of sensitivity to penicillins. F Clin Pathol 1974;27:560.

4 Wilson R, Roberts DE, Cole PJ. Products released from bacteria are toxic for human ciliary function in vitro. Thorax $1984 ; 39: 703$.

. Clinical significance of tissue penetration of antibiotics in the respiratory tract. Scand 7 Infect Dis 1978;14 (suppl): 262-6.

(Accepted 7 September 1984)

\begin{abstract}
Hitherto voice changes have been regarded as an infrequent complication of thyroidectomy and damage to the recurrent laryngeal nerve has been given as their major cause. Voice function was assessed in 325 patients after thyroidectomy. Permanent changes occurred in $35(25 \%)$ after subtotal thyroidectomy and in $19(11 \%)$ after lobectomy. The commonest cause of voice change appeared to be injury to the external laryngeal nerves on one or both sides. Damage to the recurrent laryngeal nerve, which was routinely identified and protected, was rarely a cause. When the external laryngeal nerves were identified and preserved, permanent voice changes occurred in only $5 \%$ of cases; this was similar to the incidence of $3 \%$ in controls after endotracheal intubation alone.
\end{abstract}

The course of the external laryngeal nerve is variable,

\footnotetext{
Northwick Park Hospital and Clinical Research Centre, Harrow, Middlesex

A E KARK, FRCs, consultant, department of surgery

$M W$ KISSIN, FRCS, registrar, department of surgery

R AUERBACH, FRCS, consultant, department of otolaryngology

MARGARET MEIKLE, LCST, speech therapist

Correspondence to: Mr A E Kark.
}

and consequently mass ligation of the vessels at the top of the upper pole will damage it in a high proportion of cases. To minimise this serious complication these nerves should be identified and protected as well as the recurrent nerves and voice function should be assessed early in the postoperative period by laryngoscopy and by a speech therapist.

\section{Introduction}

The safety of thyroidectomy has been enhanced by anaesthetic refinements and preoperative control of the thyroid disease, so permitting unhurried, precise surgery in euthyroid patients. Nevertheless, a few patients are affected postoperatively by hypoparathyroidism, hypothyroidism, or change in the voice. Voice changes range from slight huskiness, poor volume, and a tired voice by evening to those necessitating a complete change of leisure and professional activities.

Voice change after thyroidectomy has generally been held to be the result of damage to the recurrent laryngeal nerve. Thus identification and preservation of this nerve is widely practised. ${ }^{1}$ Some surgeons deliberately avoid dissecting the recurrent nerve, but Roy et al found unilateral damage to the recurrent laryngeal nerve in $13.3 \%$ of 300 such cases. ${ }^{2}$ Painter, reviewing operations for toxic goitre, concluded that "the integrity of the recurrent laryngeal nerves is not the only factor in the preservation of a normal voice after operation,"3 and Nash maintained that after thyroidectomy "a considerable number suffer a reduction of voice range." We encountered a disturbingly high incidence of postoperative voice changes and therefore reviewed a series of 415 patients after thyroidectomy. 


\section{Patients and methods}

We studied three groups of patients. The first group was a retrospective series of 415 patients after standard thyroidectomy, which included identification of the recurrent nerve and mass ligation of the superior thyroid vessels at or immediately below their entry to the upper pole. The disease, the extent of resection of the thyroid, and the fact that the recurrent nerve had been identified were noted from the case records. Changes of voice in pitch, range, intensity, fatigability, and quality of the singing voice were assessed by a questionnaire followed by clinical examination. Changes lasting less than six months were defined as temporary; permanent changes were classified as mild or severe according to whether or not they interfered with the patients' way of life. These patients were referred to an ear, nose, and throat surgeon (RA) for examination, including indirect laryngoscopy, and to a speech therapist (MM).

The second group of patients $(n=38)$ were studied prospectively after thyroidectomy, which included, additionally, identification and preservation of the external branch of the superior laryngeal nerve. Voice assessment was carried out as in the first group. In addition, objective voice analysis was performed before and after operation with a Visipitch oscilloscope (Visipitch TM model 6087, Kay Elemetrics Co, Pinebrook, New Jersey 07058, USA; and Wessex Electronics Ltd, Bristol BS16 5SE). This machine records the fundamental frequency of vibrations of the vocal cords in real time by extracting cycle to cycle changes with an accuracy of $1 \mathrm{~Hz}$, and provides an objective evaluation of pitch and voice quality that is reliable and reproducible.

Finally, we performed voice assessments on 100 women six months or more after modified radical mastectomy with endotracheal intubation (control series).

The incidence of voice changes was compared between the groups with two tailed Fisher's exact tests.

\section{Results}

CONTROL SERIES

Five of the 100 control patients developed voice changes; these were permanent in three, in one of whom they were severe. This showed the degree of trauma that can follow endotracheal intubation.

\section{RETROSPECTIVE SERIES}

Altogether 325 patients ( $78 \%$ ) were available for clinical assessment (table I). The remaining 90 had moved away, had died, or were

TABLE I-Number (\%) of patients with voice change after thyroidectomy

\begin{tabular}{|c|c|c|c|c|c|}
\hline & \multirow{2}{*}{$\begin{array}{c}\text { No } \\
\text { studied }\end{array}$} & \multirow{2}{*}{$\begin{array}{l}\text { Temporary } \\
\text { change }\end{array}$} & \multicolumn{3}{|c|}{ Permanent change } \\
\hline & & & Total & Mild & Severe \\
\hline $\begin{array}{l}\text { Lobectomy } \\
\text { Subtotal thyroidectomy } \\
\text { Total thyroidectomy }\end{array}$ & $\begin{array}{r}170 \\
141 \\
14\end{array}$ & $\begin{array}{l}13(8) \\
17(12) \\
3(21)\end{array}$ & $\begin{array}{r}19(11) \\
35(25) \\
5(36)\end{array}$ & $\begin{array}{r}14 \\
20 \\
3\end{array}$ & $\begin{array}{r}5 \\
15 \\
2\end{array}$ \\
\hline Total & 325 & $33(10)$ & $59(18)$ & & \\
\hline
\end{tabular}

unwilling to participate. The mean age was 44 years (range 14-76), and 283 patients were women. One hundred and sixty three patients had colloid nodular goitres and 76 toxic goitres. Lobectomy was carried out in 170 patients, subtotal thyroidectomy in 141 , and total thyroidectomy in 14 . Ninety two patients suffered voice changes: 59 were permanent changes, of which 22 were severe. Thirty eight of the 92 declined further investigation, so 54 underwent indirect laryngoscopy: this group included 42 of the 59 with permanent damage. The changes consisted of fatigue, loss of singing notes, huskiness, or hoarseness or, most commonly, a combination of two or more of these (table II).

Permanent voice problems were directly related to the extent of : section of the thyroid (table I), occurring twice as commonly after bilateral $(26 \% ; 40 / 155)$ as after unilateral $(11 \% ; 19 / 170)$ removal. Permanent damage was significantly more common after both unilateral $(p=0.02)$ and bilateral $(p<0.001)$ thyroidectomy than in the control series $(3 \%)$.
TABLE II-Numbers of patients with different permanent voice disabilities after thyroidectomy

\begin{tabular}{lcccrc}
\hline & $\begin{array}{c}\text { No } \\
\text { studied }\end{array}$ & $\begin{array}{c}\text { No with } \\
\text { permanent } \\
\text { change }\end{array}$ & Fatigue & $\begin{array}{c}\text { Loss of } \\
\text { singing } \\
\text { voice }\end{array}$ & $\begin{array}{c}\text { Hoarseness } \\
\text { or } \\
\text { combination } \\
\text { of all } \\
\text { changes }\end{array}$ \\
\hline $\begin{array}{l}\text { Lobectomy } \\
\begin{array}{l}\text { Subtotal thyroidectomy } \\
\text { Total thyroidectomy }\end{array}\end{array}$ & 170 & 19 & 6 & 5 & 8 \\
& 14 & 35 & 6 & 12 & 17 \\
\hline
\end{tabular}

Paralysis of the vocal cords occurred in seven patients (five with a permanent and two with a temporary voice change), representing an overall incidence of palsy of the nerves at risk of $1.1 \%$.

Signs of palsy of the superior laryngeal nerve were seen in two patients. These consisted of the affected cord lying at a lower level with an oblique glottic aperture.

\section{PROSPECTIVE SERIES (table III)}

The mean age of the 38 patients was 41.4 years (range 18-81), and 30 were women. Subtotal thyroidectomy was carried out in 18 . The external branch of the superior laryngeal nerve was sought in all cases; of 56 nerves at risk, 47 were found and preserved. Voice change occurred in nine patients; this was temporary in seven and permanent (and mild) in two. In both patients with permanent changes indirect laryngoscopy yielded normal findings. The incidence of permanent voice changes $(5 \%)$ was not significantly greater than that in the control series $(3 \%)$.

TABLE III-Number (\%) of patients with voice change after thyroidectomy in which external laryngeal nerves were preserved

\begin{tabular}{lccc}
\hline & No studied & $\begin{array}{c}\text { Temporary } \\
\text { change }\end{array}$ & $\begin{array}{c}\text { Permanent } \\
\text { change* }\end{array}$ \\
\hline Lobectomy & 20 & 2 & 1 \\
\hline Total & 18 & 5 & 1 \\
\hline
\end{tabular}

*All permanent changes were mild.

The Visipitch oscilloscope showed that half the patients had objective changes (more than a $20 \%$ change in range, frequency, or phonation times) a week after operation, whereas only a fifth had symptomatic subjective changes. By three months six patients $(15 \%)$ still showed measurable changes, but they did not have any subjective complaints.

\section{Discussion}

During phonation the fundamental frequency of vibration of the vocal cords depends on the size, shape, and elastic tension of the vocal folds. ${ }^{5}$ The cords assume a characteristic shape and mode of vibration for each register, being rounded, full, and relaxed for chest tones and sharp edged, thin, and taut for falsetto notes. ${ }^{6}$ The cricothyroid muscles (external laryngeal nerve) tense the cords and come into play at frequencies above $150 \mathrm{~Hz}$ and are thus particularly involved in the production of high tones of the female voice range. ${ }^{7}$ In addition, a degree of fine tuning of the voice is achieved by contraction of the vocalis muscle (the medial fibres of the thyroarytenoid), which is supplied by the recurrent laryngeal nerve.

Voice changes after thyroidectomy may be caused by damage to any of the intrinsic structures involved in this complex mechanism, as well as to extralaryngeal muscles (figure).

\section{STRAP MUSCLES}

The suprahyoid and infrahyoid strap muscles act in concert to anchor the hyoid as a platform to permit movements of 
deglutition and phonation. With the hyoid thus relatively fixed the thyrohyoid pulls the larynx up when high notes are made and the sternothyroid pulls the larynx down during low notes. The extent to which division of the strap muscles may affect laryngeal movements by lessening the stability of the hyoid is

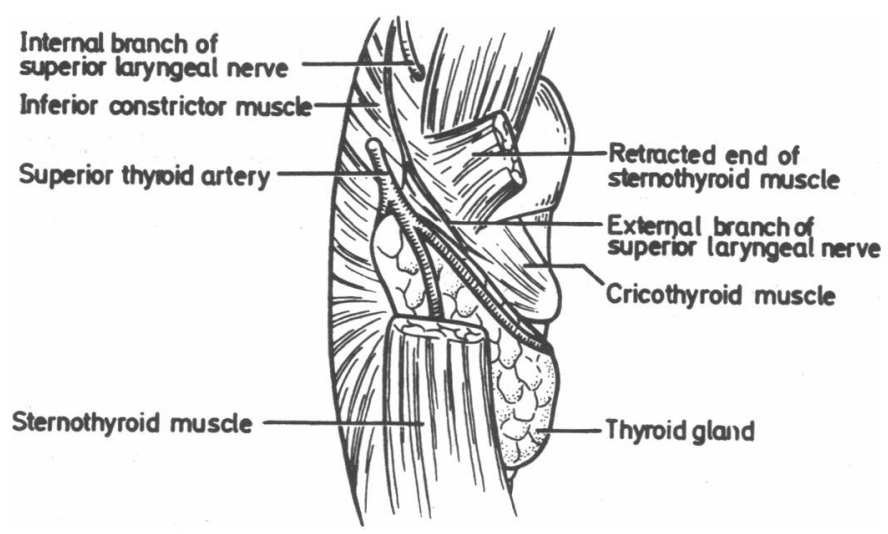

Anatomy of sternothyroid triangle.

not known. Although a large gland or heavy musculature often necessitates division, retraction as a rule has provided adequate exposure. If muscles are divided resuture is advisable, though this may not always be possible if only a thinned out sternothyroid is cut.

\section{CRICOTHYROID MUSCLES}

The cricothyroid muscles form the posteromedial border of the upper pole and vessels. During dissection electrocoagulation in this area is likely to produce muscle necrosis or damage the external laryngeal nerve. The muscle may also be torn by forcible anterior delivery of the upper pole by a finger pressed underneath the lateral side, which may damage the delicate cricothyroid or cricoarytenoid joints. The extent of injury done by these manoeuvres cannot be measured, but they should not form part of a careful thyroidectomy.

\section{EXTERNAL LARYNGEAL NERVE}

Damage to the external laryngeal nerve causes paralysis of the cricothyroid muscle. Moosman and DeWeese showed that the external branch usually lies adjacent to the inferior constrictor outside the surgical capsule of the thyroid gland. ${ }^{8}$ Thus the surgical method based on developing a plane within the surgical capsule would ordinarily separate the vessels from the nerve. In $21 \%$ of 400 dissections, however, the nerve was either adherent to, or entwined around, branches of the superior thyroid artery within the thyroid capsule. Mass ligature of the suprapolar vessels would certainly have snared the nerve in one in five of all cases. Others have noted the proximity of the nerve to the artery in an even higher proportion of cases. ${ }^{5} 9$ These anatomical variations would help explain the extent of voice damage found in our retrospective series. The external branch of the nerve may disappear into the belly of the inferior constrictor muscle well above the upper pole, and such a variation occurs in $6-15 \%$ of cases. ${ }^{10}$ In these cases the nerve, safely out of reach, usually cannot be identified; this might explain some of the nine cases in our prospective series in which the nerve could not be found.

The functional effect of damage is a lower pitched, husky voice that is easily fatigued and has a reduced range. ${ }^{6} 11$ This is more pronounced in women because of the limitation of higher frequencies and therefore particularly affects the singing voice. Moran and Castro in 1951 during removal of adenomatous goitres crushed the external laryngeal nerve with forceps. ${ }^{12}$ Unilateral trauma produced a hoarse, monotonous voice for five to seven days that then "seemed to return to normal." Bilateral damage showed the same effect plus fatigue that lasted for at least three months and in one case was permanent.

Signs of cricothyroid paralysis are subtle and may easily be overlooked when the anaesthetist has reported normal cord movements on extubation. When early voice changes then occur these are ascribed to laryngeal oedema or tracheal manipulation. The laryngoscopic changes are certainly much less clear than after palsy of the recurrent nerve. The edge of the cord affected may be irregular or wavy $^{13}$; it usually lies at a lower level, ${ }^{14}$ producing an oblique glottic aperture; and it is sometimes shortened and flaccid and bulges on expiration. Laryngoscopic diagnosis is difficult: only two such lesions were detected in this series. If the cords abduct and adduct normally all that can be deduced is that palsy of the recurrent laryngeal nerve is not the cause of any voice change present. Preoperative voice impairment associated with palsy of the external laryngeal nerve has been reported, presumably caused by an enlarged upper goitre stretching the nerve. ${ }^{11}$

Damage to the internal laryngeal nerve is much less likely. Arising from the superior laryngeal nerve, this nerve swings medially at the level of the greater cornu of the hyoid to pierce the thyroglossal membrane and become the sensory nerve of the upper larynx. It is a much larger nerve than the external branch and is at risk only when the upper pole is greatly enlarged.

There is a striking difference in prognosis after palsy of the external and of the recurrent laryngeal nerves. Unilateral damage to the recurrent nerve causes hoarseness, which later resolves almost completely in half of patients. ${ }^{215}$ Bilateral palsy causes early complete loss of voice, with recovery and return of voice function in almost half of patients. By contrast, recovery after palsy of the external nerve palsy is poor and the prognosis not good. ${ }^{6}$ Thus early diagnosis of the extent of damage and early speech therapy is important for rehabilitation of the voice.

\section{ENDOTRACHEAL INTUBATION}

Endotracheal intubation carried a hazard to the voice of $5 \%$ and caused permanent damage in 3\% of cases. Many professional singers and teachers are aware of the risk of laryngeal intubation causing damage to the delicate laryngeal and cord mechanisms, and their concern appears to be well founded. Thyroidectomy with preservation of the external laryngeal nerve carried no greater risk of voice change than did intubation alone.

\section{OPERATIVE TECHNIQUE AND CONCLUSIONS}

Preservation of the external laryngeal nerve requires firm upward retraction or division of the sternothyroid muscle and caudal retraction of the upper pole. This manoeuvre exposes the superior thyroid vessels, which are individually displayed entering the upper pole. By gentle retraction of the vascular pedicle the external laryngeal nerve can then be found running on the surface, or entering the body of the cricothyroid muscle. If it is not in this position it should be sought between the separately identified veins and artery, which are then individually ligated and divided. If it cannot be found on the cricothyroid at least its safety will have been ensured by this technique. The recurrent laryngeal nerve is identified and followed upwards to the inferior thyroid artery.

Perhaps the most famous person who sustained damage to the external laryngeal nerve was Amelita Galli-Curci, the great coloratura soprano. A slowly enlarging goitre over 15 years threatened her career. In 1935 her surgeon, using local anaesthesia, made her trill scales while he excised a $6 \mathrm{oz}(170 \mathrm{~g})$ goitre after careful display and preservation of both recurrent 
laryngeal nerves. After the operation she found that her register had fallen to that of a lyric soprano. Her voice had become coarse, and critics wrote that "the amazing voice is gone forever, instead of cream velvet there is a sad quivering ghost."16

The incidence of voice changes after thyroidectomy in our retrospective series probably underestimates the true incidence as only $78 \%$ of the patients were assessed clinically; but the vulnerability of the many components of voice production is emphasised. The external laryngeal nerves need to be as precisely identified as the recurrent laryngeal nerve, and to be protected against diathermy burns and ligation. The cricothyroid muscle and adjacent small joints should be handled gently, and the strap muscles should not be routinely sacrificed.

Voice assessment should be as much a part of follow up after thyroidectomy as are measurements of serum calcium concentrations. Laryngeal examination before and after operation by an otolaryngologist and speech therapist is advisable and should include indirect laryngoscopy and objective voice assessment. The Visipitch oscilloscope offers a sensitive measurement of voice function that will help select those requiring early intensive speech therapy.

We thank Ms Caroline Doré for statistical advice.

\section{References}

1 Anonymous. Damaged laryngeal nerves in thyroid surgery [Editorial]. $\mathrm{Br} \mathrm{Med} \mathcal{f}$ 1977; ;i:416-7.

Roy AD, Gardiner RH, Niblock WM. Thyroidectomy and the recurrent laryngeal nerve. Lancet $1956 ; \mathrm{i}: 988-9$.

Painter NS. Results of surgery in the treatment of toxic goitre-review of 172 cases. Br 7 Surg 1960;48:291-6.

the recurrent laryngeal nerves. Lancet 1956 ;ii

632 .

ader DN, Luter PW, Daniels BT. A photographic study of the superior and inferior laryngeal nerves and the superior and inferior thyroid arteries. Am f Surg 1957;23:609-18.

6 Arnold JE. Vocal rehabilitation of paralytic dysphonia. Arch Otolaryngol 1962; $75: 549-70$.

7 Scott-Brown WJ, Ballantyne JC, Groves J. Diseases of the ear, nose and throat. 4th ed. London: Butterworth, 1979.

Moosman DA, DeWeese MS. The external laryngeal nerve as related to thyroidectomy. Surg Gynecol Obstet 1968;127:1011-6.

9 Durham CF, Harrison TS. The surgical anatomy of the superior laryngeal nerve. Surg Gynecol Obstet 1964;118:38-44.

10 Norland $M$. The larynx as related to surgery of the thyroid based on an anatomical

11 Newman AN, Becker SP. Superior laryngeal nerve paralysis and benign thyroid

Moran RE, Castro AF. The superior laryngeal nerve in thyroid surgery. Ann Surg 1951;134:1018-21.

13 Beyer TE. Traumatic paralysis of the cricothyroid muscle. Laryngoscope 1941; $51: 296-8$.

14 Hunt $C J$. The superior and inferior laryngeal nerve as related to thyroid surgery. Am $\mathcal{F}$ Surg 1961;27:548-52

15 Watt-Boolsen S, Blichert-Toft M, Hanse JB, Jorgensen SJ, Boberg A. Late voice function after injury to the recurrent nerve. Clin Otolaryngol 1977;2:191-7. 16 Anonymous. Brave return [Music column]. Time 1936 Dec 7.

\title{
Spleen size in chronic renal failure
}

\author{
M M PLATTS, E ANASTASSIADES, S SHERIFF，S SMITH， D C C BARTOLO
}

\begin{abstract}
To investigate the cause of clinically detectable splenomegaly, which is common in patients receiving regular haemodialysis, splenic volume was assessed by isotopic scanning using intravenously injected technetium-99m microspheres in 34 controls and 149 patients with chronic renal failure. Of the patients, 16 had never received dialysis, 10 were undergoing continuous peritoneal dialysis, 94 were undergoing regular haemodialysis, and 29 had undergone successful renal transplantation more than nine months previously. Mean splenic volume was increased only in the patients who were receiving haemodialysis. Splenic enlargement was probably not due to iron overload as it occurred in all patients who had received haemodialysis, 14 of whom had not received intravenous iron. No patient had had hepatitis.

Splenic enlargement was probably related to the process of haemodialysis itself and may have been due either to red cell damage produced by haemodialysis or to an immunological reaction induced by a component of haemodialysis, possibly ethylene oxide.
\end{abstract}

\footnotetext{
Departments of Medicine, Medical Physics, and Surgery, Royal Hallamshire Hospital, Sheffield S10 2JF

M M PLATTS, MD, FRCP, reader in medicine (retired)

E ANASTASSIADES, BSC, MRCP, research assistant

S SHERIFF, BMEDSCI, senior physicist

S SMITH, SRN, research assistant

D C C BARTOLO, MB, FRCS, surgical registrar
}

Correspondence and requests for reprints to: $\mathrm{Dr} M \mathrm{M}$ Platts, 47 Colnwell Lane, Sheffield S10 5TJ.

\section{Introduction}

During routine examination we are able to feel the spleen in many of our patients receiving regular haemodialysis. Others have observed that spleens removed from such patients for the treatment of refractory anaemia, ${ }^{1-4}$ in preparation for renal transplant, ${ }^{5}$ or at postmortem examination ${ }^{6}$ are usually enlarged. We know, however, of no survey of the prevalence of splenomegaly in patients with chronic renal failure. We therefore measured splenic volume by radioisotope imaging in patients with chronic renal failure who had not received dialysis, were being treated by continuous ambulatory peritoneal dialysis or regular haemodialysis, or had undergone successful renal transplantation and compared these volumes with those found in patients with normal renal function.

\section{Subjects and methods}

Between 1979 and early 1982 we carried out a survey on patients in Sheffield with chronic renal failure who had undergone a single method of treatment for at least nine months. Patients who had polycystic disease or amyloidosis or who were acutely ill or infected were excluded because of the effect of these conditions on splenic size. Patients were also excluded if they were unwilling, once the nature of the investigation had been explained to them, to undergo scanning of the spleen.

We selected 34 control subjects, five of whom were healthy members of the hospital staff. The others were a consecutive series of adults aged under 70 with normal renal function and normal liver scans. Seven had been referred for liver scanning because of abdominal pain, four because of abnormal results to liver function tests, one because of porphyria, and five because of a clinical impression of hepatomegaly. Thirteen others had had neoplastic disease and were being investigated for the presence of secondary deposits; we used the spleen scans obtained incidentally during these investigations. 